JURNAL SEKRETARIS DAN ADMINISTRASI BISNIS

Journal homepage: http:/ljurnal.asmtb.ac.id

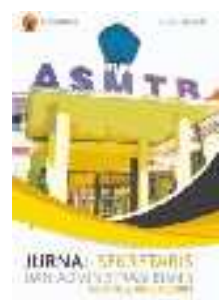

The Effect of Public Relations on Brand Image and Impact on Customer Loyalty: A Case of Aston Braga Hotel \& Residence Bandung

\title{
Pengaruh Public Relations terhadap Brand Image dan Dampaknya terhadap Loyalitas Konsumen: Kasus pada Aston Braga Hotel \& Residence Bandung
}

${ }^{1)}$ Mochamad Alief; ${ }^{2)}$ Muhammad Yahya Arwiyah,

1,2) Prodi Administrasi Bisnis, Telkom University

1) realalief@student.telkomuniversity.ac.id; ${ }^{2)}$ yahya.staff@telkomuniversity.ac.id

Article info

Article history:

Received $17^{\text {th }}$ December 2019

Received in revised form $26^{\text {th }}$ June 2020

Accepted $14^{\text {th }}$ July 2020

Keywords:

Public Relations,

Brand Image,

Customers Loyalty

\begin{abstract}
This research is backed by problems related to Public Relatons and Brand Image at Aston Braga Hotel \& Residence Bandung. The problem is based on the results of pre-survey that shows that Brand Image have not fully received a good response from the respondent. But in the year 2018 describes the customer loyalty to loyal to Aston Braga decreased, in this research the author wants to examine whether this decline is caused by Public Relations or Brand Image. Where more and more competitors are uplifting business people to further enhance their consumer brand and loyalty. This research aims to know how much Public Relations influence the Brand Image and its impact on consumer loyalty Aston Braga Hotel \& Residence Bandung.The method used in this research is a quantitative method with the type of research used is descriptive verificative, the scale of measurement used is Likert scale. This Peelitian population is a consumer of Aston Braga Hotel \& Residence Bandung with a sample of 100 respondents. The sampling techniques used in this study are nonprobability sampling. The data analysis method used in this research is Path analysis path. Data processing is done using SPSS. Based on the research conducted, the percentage of Public Relations assessments entered in good category with a value range of $68 \%-84 \%$, while the Brand Image assessment percentage and consumer loyalty were good enough with a value range of $52 \%-68 \%$.
\end{abstract}




\section{Pendahuluan}

Bandung merupakan salah satu kota di Indonesia yang menawarkan banyak sekali tempat wisata, baik wisata alam, tempat kuliner, mall ,dan factory outlet. Hal tersebut membuat Kota Bandung menjadi sangat diminati oleh para wisatawan domestik atau mancanegara. Seiring dengan semakin berkembangnya daya tarik wisata yang ada di Kota Bandung, karena hal tersebutlah yang membuat Kota Bandung semakin terkenal, yang pada akhirnya akan berdampak pada industri perhotelan tersebut menjadi makin diminati.

Tabel 1

Daftar Wisatawan yang Berkunjung ke Bandung

\begin{tabular}{|c|c|c|c|}
\hline \multirow{2}{*}{ Iulizar } & \multicolumn{2}{|c|}{ Wisatawan } & \multirow{2}{*}{ f-rulah } \\
\hline & Mancanegara & Comestik & \\
\hline $20 \leq 1$ & 225 S85 & $048 / 255$ & $0112=24$ \\
\hline 2012 & $1 / 6$ sbs & $=080 \leq 44$ & נפגד ;25 \\
\hline $20 \pm 3$ & 176492 & 9388252 & $556 \angle 724$ \\
\hline 2014 & $180=43$ & $=6221<21$ & $\leq 80 / \leq 64$ \\
\hline 2015 & 18.39 .57 & 5877167 & ก 061094 \\
\hline 2016 & $17.30 .5 \%$ & 4827589 & $5000 \times>5$ \\
\hline
\end{tabular}

Sumber: Dinas Pariwisata dan Kebudayaan Kota Bandung, 2017

Pada dasarnya, industri perhotelan saat ini merupakan salah satu industri jasa yang berkembang dengan pesat. Adanya dorongan dari pemerintah untuk mengembangkan industri perhotelan seiring dengan adanya peningkatan jumlah wisatawan yang datang ke Kota Bandung, maka kebutuhan jasa perhotelan meningkat dengan pesat. Hal ini dapat dilihat dengan banyaknya didirikan hotel-hotel baru di Bandung.

Tabel 2

Total Jumlah Hotel dan Kamar di Kota Bandung Tahun 2018

\begin{tabular}{|c|c|c|}
\hline Jenis Hotel & Jumlah Hotel & Jumlah Kamar \\
\hline Bintang 5 & 9 & 1890 \\
\hline Bintang 4 & 32 & 3748 \\
\hline Bintang 3 & 55 & 3508 \\
\hline Bintang 2 & 43 & 1500 \\
\hline Bintang 1 & 57 & 400 \\
\hline Non Bintang & 279 & 6010 \\
\hline Total & 475 & 17.058 \\
\hline
\end{tabular}

Sumber:http://data.bandung.go.id/dataset/, 2019

Menurut Adreani (2007:04) dalam Alkilani et.al (2013) Diiringi dengan ketatnya persaingan bidang usaha industri perhotelan di era digital saat ini adalah salah satu alasan utama terciptanya ragam produk dan ragam fasilitas serta pelayanan yang disuguhkan para pengusaha bisnis kepada 
konsumen. Dalam menghadapi persaingan itu, sebuah perusahaan ataupun seorang pemasar harus memiliki keunggulan bersaing untuk dapat terus bertahan pada produk dan jasa yang mereka tawarkan pada konsumen. Karena pada saat ini, konsumen menganggap fungsi, fitur, kualitas produk serta brand image yang positif sebagai hal yang biasa atau umum.

Perkembangan industri perhotelan yang semakin ketat membuat Aston Braga Hotel \& Residence harus mampu bersaing dalam menghadapi berbagai ancaman yang ada di industri hotel baik itu dari segi kompetitor, ataupun hal lainnya seperti faktor persaingan dalam industri, kekuatan pemasok, kekuatan pembeli, dan ancaman produk subtitusi.

MenurutFour As (The American Association of Advertising Agency) dalamGeorge E. BleachTahun 2006, "Banyak cara yang dilakukan dalam mengembangkan bisnis di industri perhotelan, strategi itu antara lain dengan menggunakan iklan, direct response, promosi penjualan, dan Public Relations." Public relations dalam dunia perhotelan telah menjadi hal yang tidak asing lagi, beberapa hotel berbintang tidak melewatkan public relations sebagai penunjang keberhasilan perusahaannya. Public Relations merupakan bagian dari struktur organisasi dalam suatu perusahaan yang memiliki tugas untuk menciptakan citra merek yang baik dimata publik dan memperbaiki serta mengembalikan citra perusahaan agar tetap berarti dimata publik.

Perkembangan industri perhotelan yang semakin ketat membuat Aston Braga Hotel \& Residence harus mampu bersaing dalam menghadapi berbagai ancaman yang ada di industri hotel baik itu dari segi kompetitor, ataupun hal lainnya seperti faktor persaingan dalam industri, kekuatan pemasok, kekuatan pembeli, dan ancaman produk subtitusi.Hal ini menjadi masalah yang harus diselesaikan oleh Manajemen Aston dengan cara menyusun strategi komunikasi dengan berbagai pihak agar memiliki hubungan yang baik dan tentunya meningkatkan citra baik Aston Braga Hotel \& Residence Bandung sehingga terciptanya konsumen yang loyal dalam artian ketika mengunjungi Bandung, wisatawan akan memilih Aston Braga Hotel \& Residence. Berdasarkan pemaparan tersebut penulis tetarik melakukan penelitian ini dengan judul "Pengaruh Public Relations Terhadap Brand Image dan Dampaknya Terhadap Loyalitas Konsumen (Studi pada Aston Braga Hotel \& Residence Bandung). Berdasarkan latar belakang yang sudah diuraikan sebelumnya, adapun perumusan masalah yang diangkat pada penelitian ini yaitu:

1) Bagaimana Public RelationsterhadapBrand ImagepadaAston Braga Hotel \& Residence ?

2) Bagaimana Brand Imageterhadap customer loyalty pada Aston Braga Hotel \& Residence ?

3) Bagaimana pengaruh langsung Public Relationsterhadap Customer Loyalty dan pengaruh Public Relationsterhadap customer loyalty yang dimediasi oleh Brand Imagepada Aston Braga Hotel \& Residence?

\section{Public Relations}

Menurut Menurut Kotler dan Keller (2016:582) Public Relationsadalah berbagai program yang diarahkan secara internal kepada karyawan perusahaan atau eksternal kepada konsumen, perusahaan lain, pemerintah, dan media untuk mempromosikan atau melindungi citra perusahaan atau komunikasi produk individualnya. Menurut Kotler and Keller (2006:553) dalam Sitepu, Kumadji, dan Wilopo (2015:04) ada tujuh cara penting untuk menjadi tolak ukur dalam kegiatan Marketing Public Relations yaitu:

1) Publication (Publikasi)

Perusahaan secara ekstensif mengandalkan bahan-bahan yang diterbitkan untuk mencapai dan mempengaruhi pasar sasaran mereka. Ini termasuk laporan tahunan, brosur, artikel, berita perusahaan dan majalah, dan bahan-bahan audiovisual 
Perusahaan perlu identitas visual yang umum. Identitas visual dibawa oleh logo perusahaan, alat tulis, brosur, tanda, bentuk-bentuk bisnis, kartu nama, bangunan, seragam, dan berpakaian.

3) Events

Perusahaan dapat menarik perhatian produk baru atau kegiatan perusahaan dengan mengatur acara khusus seperti berita konferensi, seminar, acara, pameran dagang, pameran, kontes dan kompetisi, dan peringatan yang akan mencapai target publik.

4) News (Berita)

Salah satu tugas utama dari PR profesional adalah untuk menemukan atau membuat berita tentang perusahaan, produk, dan orang-orang, dan untuk mendapatkan media untuk menerima siaran pers dan menghadiri konferensi pers.

5) Speeches (Pidato)

Memberikan sambutan adalah tugas seorang Public Relations. Seperti kegiatan anniversary, kegiatan sosial, kerjasama, dan lain-lain.

6) Public Service Aktivities (Pelayanan Aktivitas Publik)

Perusahaan dapat membangun niat baik dengan beragam kegiatan sosial.

7) Sponsorship (Pensponsoran)

Perusahaan dapat mempromosikan merek dan nama perusahaan dengan mensponsori acaraacara kebudayaan yang dianggap sangat berpengaruh.

\section{Brand Image}

Menurut Keller (2013:346) citra merek adalah persepsi dan keyakinan yang dilakukan oleh konsumen, seperti tercermin dalam asosiasi yang terjadidalam memori konsumen. Sedangkan, menurut Wijaya (2013:62) menyimpulkan bahwa dimensi-dimensi utama yang mempengaruhi dan membentuk citra sebuah merek,antara lain

1) Brand Identity

Dimensi pertama adalah brand identity atau identitas merek. Brand identity merupakan identitas fisik yang berkaitan dengan merek atau produk tersebut sehingga konsumen mudah mengenali dan membedakannya dengan merek atau produk lain, seperti logo, warna, kemasan, lokasi, identitas perusahaan yang memayunginya, slogan, dan lain-lain

2) Brand Personality

Dimensi kedua adalah brand personality atau personalitas merek. Brand personality adalah karakter khas sebuah merek yang membentuk kepribadian tertentu sebagaimana layaknya manusia, sehingga khalayak konsumen dengan mudah membedakannya dengan merek lain dalam kategori yang sama, misalnya karakter tegas, kaku, berwibawa, ningrat, atau murah senyum, hangat, penyayang, berjiwa sosial, atau dinamis, kreatif, independen, dan sebagainya.

3) Brand Association

Dimensi ketiga adalah brand association atau asosiasi merek. Brand association adalah halhal spesifik yang pantas atau selalu dikaitkan dengan suatu merek, bisa muncul dari penawaran unik suatu produk, aktivitas yang berulang dan konsisten misalnya dalam hal sponsorship atau kegiatan social responsibility, isu-isu yang sangat kuat berkaitan dengan merek tersebut, ataupun person, simbol-simbol dan makna tertentu yang sangat kuat melekat pada suatu merek. 
Dimensi keempat adalah brand attitude atau sikap dan perilaku merek. Brand attitude and behavior adalah sikap atau perilaku komunikasi dan interaksi merek dengan konsumen dalam menawarkan benefit-benefit dan nilai yang dimilikinya. Kerap sebuah merek menggunakan cara-cara yang kurang pantas dan melanggar etika dalam berkomunikasi, pelayanan yang buruk sehingga mempengaruhi pandangan publik terhadap sikap dan perilaku merek tersebut, atau sebaliknya, sikap dan perilaku simpatik, jujur, konsisten antara janji dan realitas, pelayanan yang baik dan kepedulian terhadap lingkungan dan masyarakat luas membentuk persepsi yang baik pula terhadap sikap dan perilaku merek tersebut. Jadi brand attitude and behavior mencakup sikap dan perilaku komunikasi, aktivitas dan atribut yang melekat pada merek saat berhubungan dengan khalayak konsumen, termasuk perilaku karyawan dan pemilik merek.

5) Brand Benefit \& Competence

Dimensi kelima adalah brand benefit and competence atau manfaat dan keunggulan merek. Brand benefit and competence merupakan nilai-nilai dan keunggulan khas yang ditawarkan oleh suatu merek kepada konsumen yang membuat konsumen dapat merasakan manfaat karena kebutuhan, keinginan, mimpi dan obsesinya terwujudkan oleh apa yang ditawarkan tersebut. Nilai dan benefit di sini dapat bersifat functional, emotional, symbolic maupun social, misalnya merek produk deterjen dengan benefit membersihkan pakaian (functional benefit/values), menjadikan pemakai pakaian yang dibersihkan jadi percaya diri (emotional benefit/values),

menjadi simbol gaya hidup masyarakat modern yang bersih (symbolic benefit/values), dan memberi inspirasi bagi lingkungan untuk peduli pada kebersihan diri, lingkungan dan hati nurani (social benefit/values). Manfaat, keunggulan dan kompetensi khas suatu merek akan memengaruhi brand image produk, individu atau lembaga/perusahaan tersebut.

\section{Loyalitas Konsumen}

Pengertian loyalitas pelanggan menurut Fandy Tjiptono (2014:110) adalah: "loyalitas pelanggan sebagai komitmen pelanggan terhadap suatu merek, toko, pemasok berdasarkan sikap yang sangat positif dan tercermin dalam pembelian ulang yang konsisten”.Menurut Zeithaml, et al. (1996 : 38) dalam jurnal Rahma Nindyastari (Telkom University : 2014) menyatakan ada beberapa atribut pada loyalitas konsumen, antara lain :

1) Mengatakan hal yang positif tentang perusahaan kepada orang lain.

2) Merekomendasikan perusahaan kepada orang lain yang meminta saran.

3) Mempertimbangkan bahwa perusahaan merupakan pilihan pertama dalam melakukan pembelianjasa

4) Melakukan lebih banyak bisnis atau pembelian dengan perusahaan pada beberapa tahun mendatang.

\section{Pengaruh Public Relations terhadap Brand Image}

Menurut Kotler \& Keller (2016:582) “Public Relations ialah berbagai program yang diarahkan secara internal kepada karyawan perusahaan atau eksternal kepada konsumen, perusahaan lain, pemerintah, dan media untuk mempromosikan atau melindungi citra perusahaan atau komunikasi produk individualnya”. 


\section{Pengaruh Public Relations terhadap Loyalitas Konsumen}

Menurut Vanessa (2014:94) Public Relations merupakan komunikasi yang dapat dipercaya untuk menjembatani perusahaan dengan konsumennya dengan tujuan menambah nilai pelanggan dan merangsang pembeli serta kepuasan konsumen dan sekaligus membentuk kesan terhadap perusahaan.

\section{Pengaruh Brand Image terhadap Loyalitas Konsumen}

Untuk mempengaruhi minat beli konsumen, perusahaan harus meningkatkan brand image-nya secara keseluruhan, karena "Syarat merek yang kuat adalah brand image"(Kotler, 2016). Semakin kuat Brand image di benak pelanggan maka semakin kuat pula rasa percaya diri pelanggan untuk tetap loyal atau setia terhadap produk yang dibelinya sehingga hal tersebut dapat mengantar sebuah perusahaan untuk tetap mendapatkan keuntungan dari waktu kewaktu.

\section{Kerangka pemikiran}

Kerangka penelitian dapat digambarkan seperti berikut:

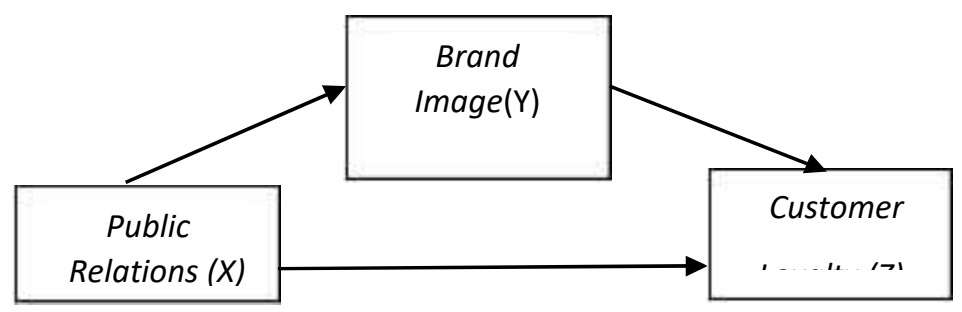

Gambar 1

Kerangka pemikiran

Sumber: hasil olah peneliti, 2019

\section{Metedologi penelitian}

Penelitian ini menggunakan metode pendekatan kuantitatif. Jenis penelitian ini adalah kausal untuk mengetahui sebab dan akibat. Lokasi penelitian yaitu Aston Braga Hotel \& Residence Bandung. Populasi reponden adalah seluruh pelanggan Aston Braga yang pernah merasakan fasilitas menginap dan meeting. Untuk menentukan sampel menggunakan rumus Bernoulli dengan hitungan N = 96,04 => 96 dibulatkan menjadi 100 maka responden berjumlah 100 orang yang merupakan konsumenAston Braga Hotel \& Residence.TeknikSamplingyangdigunakanpadapenelitian ini yaitu nonprobality sampling dan purposive sampling. Teknik pengumpulan data melalui data primer dan data sekunder. Teknik analisis data pada penelitian ini yaitu anaslisis deskriptif dan analisis inferensial dengan menggunakan path analysis. Path analysis digunakan untuk menguji pengaruh antara variabel Public Relations terhadap BrandImage dan dampaknya terhadap loyalitas pelanggan. Penelitian ini dilakukan selama 4bulan terhitung bulan September, Oktober, November, hingga Desember 2019. Variabel operasional yang digunakan yaitu variabel independen Public Relations(X), Brand Image (Y), dan variabel dependen Customer Loyalty (Z). 


\section{Hasil dan diskusi}

\section{Uji validitas dan reliabilitas}

Berdasarkan perhitungan SPSS, diperoleh $\mathrm{r}$ hitung untuk 28 item pernyataan pada variabel Public Relations(X), Brand Image(Y), dan Customer Loyalty (Z) nilainya melebihi batas kritis yang ditentukan yaitu 0,361 maka penelitian ini valid. Diperoleh koefisien Cronbach's Alpha nilainya melebihi batas kritis yang ditentukan yaitu 0,7 maka penelitian ini dapat diterima dan reliabel.

\section{Analisis deskriptif}

Analisisdeskriptifdigunakanuntukmengetahuigambaranpersepsi100respondenmengenaivariabel penelitian yaitu Public Relations, Brand Image, dan Customer Loyalty pada Aston Braga Hotel \& Residence Bandung didapatkan hasil sebagaiberikut:

Tabel 3

Total respondent Public Relations, Brand Image, customer loyalty

\begin{tabular}{|c|c|c|}
\hline Variabel & $\%$ Skor & Kategori \\
\hline Public Relatons & $71,60 \%$ & Baik \\
\hline Brand Image & $65,60 \%$ & $\begin{array}{c}\text { Cukup } \\
\text { Baik }\end{array}$ \\
\hline Customer Loyalty & $71,25 \%$ & Baik \\
\hline
\end{tabular}

Sumber: hasil olah peneliti, 2019

\section{Uji asumsi klasik}

Pada penelitian ini uji asumsi klasik meliputi uji normalitas, uji multikolinieritas, dan uji heteroskedastisitas dengan bantuan software SPSS versi 23. Uji normalitas terdapat nilai sig berasda diatas 0,05 dapat dikatakn bahwa model regresi berdistribusi normal. Uji multikolinieritas nilai tolerancediatas0,1dan VIFkurangdari10dapatdisimpulkanbahwatidakterdapatmultikolinearitas. Ujiheteroskedastisitasdilihatdariscatterplotmenunjukkantitik-titikmenyebardantidakmembentuk pola dengan jelas, dapat dikatakan tidak terjadi masalahheteroskedastisitas.

\section{Analisis jalur (path analysis)}

Pengaruh Public Relations terhadap Brand Image

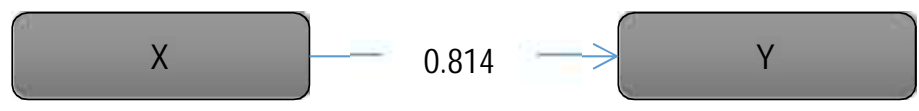

T hitung $=13.890$

Gambar 2

Uji hipotesis Public Relationsterhadap Brand Image sumber: hasil olah data peneliti, 2019 
Berdasarkan nilai standardized coefficients beta terdapat pengaruh hubungan antara Public Relations dengan Brand Imagesebesar 0,814. Diperoleh t-hitung sebesar 13.890 dan $d f=98$ diperoleh angka t tabel 1,985, sehingga t-hitung > t-tabel. Maka terdapat pengaruh signifikan antara Public Relationsterhadap Brand Image. Dengan demikian hipotesis yang menyatakan bahwa terdapat pengaruh antara Public Relationsterhadap Brand Image dapat diterima.

Pengaruh Public Relationsterhadap Customer Loyalty

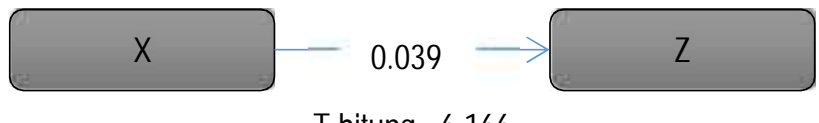

T hitung $=6.166$

Gambar 3

Uji hipotesis Public Relations terhadap customer loyalty

Sumber: hasil olah data peneliti, 2018

Berdasarkan nilai standardized coefficients beta terdapat pengaruh hubungan Public RelationsdenganCustomerLoyaltysebesar0,039.Diperoleht-

hitungsebesar6,166dan $d f=97$ diperolehangka $\mathrm{t}$ tabel 1,985, sehingga t-hitung > t-tabel. Maka terdapat pengaruh signifikan antara Public Relationsterhadap Customer Loyalty. Dengan demikian hipotesis yang menyatakan bahwa terdapat pengaruh antara Public Relationsterhadap Customer Loyalty dapatditerima.

Pengaruh Public Relationsterhadap Brand Image dan dampaknya terhadap Loyalitas Pelanggan

Tabel 4

Uji hipotesis $\mathrm{X}, \mathrm{Y}, \mathrm{Z}$

ANOVA $^{3}$

\begin{tabular}{|c|c|c|c|c|c|c|}
\hline \multicolumn{2}{|c|}{ Model } & $\begin{array}{l}\text { Sum of } \\
\text { Squares }\end{array}$ & df & $\begin{array}{l}\text { Mean } \\
\text { Square }\end{array}$ & $\mathrm{F}$ & Sig. \\
\hline \multirow[t]{3}{*}{1} & Regression & 2202.699 & 2 & 1101.349 & 196.981 & $.000^{6}$ \\
\hline & Residual & 542.341 & 97 & 5.591 & & \\
\hline & Total & 2745.040 & 99 & & & \\
\hline
\end{tabular}

a. Dependent Variable: $z$

b. Predictors: (Constant), $y_{t} x$

Sumber: hasil olah data peneliti, 2019

Berdasarkan tabel di atas, diperoleh Fhitung= 196,981> Ftabel = 3,09. Maka secara simultan variabel Public Relations dan Brand Image memiliki pengaruh terhadap variabel loyalitas pelanggan sebesar 196,981 atau sama dengan H0 ditolak dan H4 diterima yaitu bahwa ada pengaruh Public Relations dan Brand Image terhadap loyalitas pelanggan secara bersama-sama. 
Tabel 5

Uji R secara Simultan

Model Summary ${ }^{k}$

\begin{tabular}{|c|c|c|c|c|}
\hline Moce & R & $\begin{array}{c}\mathrm{R} \\
\text { Square }\end{array}$ & $\begin{array}{l}\text { Ad uoted F } \\
\text { Squale }\end{array}$ & $\begin{array}{l}\text { Stc. Error of the } \\
\text { Estimate }\end{array}$ \\
\hline 1 & $84 i^{\circ}$ & .802 & .798 & 2.36456 \\
\hline
\end{tabular}

Sumber: hasil olah data peneliti, 2019

Besarnya nilai R square (R2) pada tabel diatas adalah $0,802=80,2 \%$. Angka tersebut bermakna besarnya pengaruh variabel Public Relations (X) terhadap loyalitas pelanggan (Z), dengan demikian keputusan H3 dan H4 diterima yaitu terdapat pengaruh Public Relations, Brand Image terhadap loyalitas pelanggan sebesar 80,2 \% dan sisanya 19,8\% dipengaruhi oleh variabel lain diluar penelitian

\section{Pengaruh total Public Relationsterhadap Brand Imagedan dampaknya terhadap Customer Loyalty}

Berikut ini adalah hasil koefisien determinasi dari tiap-tiap analisis jalur pengaruh langsung Public Relationsterhadap Brand Image, pengaruh langsung Public Relationsterhadap Customer Loyalty, pengaruh langsung Brand Imageterhadap Customer Loyalty, serta pengaruh tidak langsung Public Relationsterhadap Brand Imagedan Customer Loyalty.

Tabel 6

Pengaruh total Public Relations, Brand Image, dan Loyalitas Konsumen

\begin{tabular}{|c|r|c|c|c|}
\hline \multirow{2}{*}{ Variabel } & $\begin{array}{c}\text { Koefisien } \\
\text { Jalur }\end{array}$ & Langsung & Tidak Langsung & Total \\
\cline { 3 - 5 } & 0,814 & $\begin{array}{c}0,814^{2}= \\
0,663\end{array}$ & - & 0,663 \\
\hline X terhadap Y & 0,896 & $\begin{array}{c}0,896^{2}= \\
0,802\end{array}$ & - & 0,802 \\
\hline Y terhadap Z & 0,039 & 0,039 & $0,663 \times 0,802=0,532$ & 0,571 \\
\hline X terhadap Z & 0,198 & - & - & 0,198 \\
\hline e1 & 0,198 & - & - & 0,198 \\
\hline e2 & & & & - \\
\hline
\end{tabular}

Sumber: hasil olah data peneliti, 2019

\section{Simpulan}

Penelitian diatas dapat disimpulkan bahwa berdasarkan hasil analisis variabel-variabel tersebut memiliki pengaruh antara satu variabel dengan variabel lainnya. Public Relations terhadap Brand Image,Public Relations terhadapcustomerloyalty,Brand Image terhadap customerloyalty.Hanya saja pada penelitian ini ternyata besaran pengaruh langsung nilainnya lebih kecil dibandingkan besar pengaruh tidak langsung antara Public Relations terhadap Brand Image dan Loyalitas Pelanggan. 


\section{Arah penelitian di masa depan}

Berdasarkan hasil analisis deskriptif secara keseluruhan variabel Loyalitas Konsumen pada Aston Braga Hotel \& Residence Bandung masuk ke dalam kategori baik dengan skor total 2.850 atau sebesar 71,25\%. Hal ini berdasarkan penelitian Tri Akbar Vellayati (2014) meyatakan bahwa Loyalitas Konsumen Aston Braga Hotel \& Residence Bandung masuk dalam kategori baik. Konsumen mempertimbangkan untuk melakukan keputusan menginap di Aston Braga Hotel \& Residence dengan cara mencari informasi sebanyak-banyaknya terkait dengan citra merek Aston Braga.

Dari analisis jalur sub-struktur satu, berdasarkan hasil uji t variabel Public Relations dengan Brand Image memperoleh nilai t hitung $>\mathrm{t}$ tabel yaitu, 13,890 > 1,980 dan nilai (sig) $=0,000<0,05 \mathrm{Hal}$ ini menunjukan adanya hubungan yang signifikan antara variabel Public Relations (X) dengan variabel Brand Image (Y). Semakin baik kerja tim Public Relations yang dilakukan maka akan semakin baik pula image positif yang dapat dilihat pada kolom Rsebesar 0,814 yang masuk dalam kategori sangat kuat. Secara parsial Public Relations berpengaruh positif dan signifikan terhadap Brand Image. Besaran pengaruhnya sebesar 0,663 atau $66,3 \%$ sedangkan sisanya $33,7 \%$ dipengaruhi faktor lain.

Dari analisis jalur sub-struktur dua, berdasarkan hasil uji t variabel Brand Image dengan loyalitas pelanggan memperoleh nilai thitung $>\mathrm{t}$ tabel yaitu, 19,919 > 1,980 dan nilai (sig) $=0,000<0,05 \mathrm{Hal}$ ini menunjukan adanya hubungan yang signifikan antara variabel Brand Image (Y) dengan loyalitas pelanggan (Z). Semakin tinggi Brand Image Aston Braga maka akan semakin tinggi pula tingkat loyalitas pelanggan yang dapat dilihat pada kolom Rsebesar 0,896 yang masuk dalam kategori korelasi sangat kuat. Secara parsial Brand Image berpengaruh positif dan signifikan terhadap loyalitas pelanggan. Besaran pengaruhnya sebesar 0,802 atau 80,2\% sedangkan sisanya 19,8\% dipengaruhi faktor lain.

Pada analisis jalur sub-struktur tiga, nilai $(\mathrm{sig})=0,000<0,05 \mathrm{Hal}$ ini menunjukan adanya hubungan yang signifikan antara variabel Public Relations (X) terhadap variabel loyalitas pelanggan (Z) memiliki pengaruh secara langsung hanya sebesar 0,039 atau dalam persen sebesar 3,9\%. Dimana pengaruh secara langsung tersebut sangatlah lemah. Sedangkan pengaruh jika melalui variabel Brand Image (Y) atau secara tidak langsung memiliki nilai yang lebih besar yaitu sebesar 0,532 . Serta kekuatan korelasi dapat dilihat pada kolom Rsebesar 0,896 yang masuk dalam kategori korelasi sangat kuat. Secara simultan pengaruh $\mathrm{X}$ dan $\mathrm{Y}$ terhadap $\mathrm{Z}$ adalah sebesar 0,802 atau dalam persen sebesar $80,2 \%$ sedangkan sisanya $19,8 \%$ dipengaruhi faktor lain.

Penelitian ini hanya meneliti tentang pengaruh Public Relations terhadap Brand Image dan dampaknya terhadap Loyalitas PelangganAston Braga Hotel \& Residence Bandung. Untuk penelitian selanjutnya disarankan :

1) diharapkan untuk menambah jumlah responden pada penelitian. Agar menambah keakuratan data mengenai Public Relations,Brand Image dan Loyalitas Konsumen.

2) Penelitian selanjutnya diharapkan responden menambah referensi objek penelitian terhadap Hotel lain, sehingga bisa mengetahui kualitas Brand Image Hotel lain.

3) Penelitian selanjutnya dapat menggunakan software bantuan yang berbeda selainSPSS, misalnya seperti, SmartPLS, Lisrel, ataupun AMOS. 


\section{Referensi}

Achmad Kuncoro, Engkos dan Ridwan. (2013). Cara Menggunakan dan Memakai Analisis Jalur (Path Analysis). Bandung: Alfabeta.

Alief Mochamad. (2018). Pengaruh Public Relations Terhadap Brand Image Aston Braga Hotel \& Residence. e-Proceeding of Applied Science : Vol.4, No.3 Desember 2018. Telkom University

An-Tien, Chung-kai. (2014). The Moderating Effect of Brand Image on Public Relations Perceptions and Customer Loyalty. Ling Tung University, Taiwan

Astriana Febrisari. (2016). Analisis Pengaruh Public Relations Persepsion Terhadap Brand Image dalam Membentuk Loyalitas Pelanggan Asuransi Garda OTO JABODETABEK. Jurnal Institut Pertanian Bogor

Budiasih, Yanti. 2013. Statistik Deskriptif untuk Ekonomi dan Bisnis. Tangerang: Jelajah Nusa.

Dian Nuswanto, (2018), Faculty of Economics and Business, University, Effects Of Product Quality, Price, And Brand Image On The Buying Decision Of City Car Product

Dinawan. 2013. Kualitas Produk : Alat Strategi Yang Penting, Free Press. PT Raja Grafindo Persada.Jakarta.

Drummond, Helga. 2003. Pengambilan Keputusan yang Efektif. Jakarta: PT Gramedia Pustaka Utama Freddy. R. 2013. The Power of Brand. Jakarta: PT Gramedia Pustaka Utama.

Chia Hung-Hung. (2015). The Effect of Brand Image On Public Relations and Customer Loyalty. Ling Tung University Taiwan

Fatimah Abdillah. (2017). Efektivitas Marketing Public Relation dalam membangun citra merek perusahaan jasa telekomunikasi. Jurnal Ecodemica, Vol.1 No.1 April 2017

Ghozali, Imam. (2013). Aplikasi Analisis Multivariate dengan Program SPSS.Edisi Ketujuh. Semarang: Badan Penerbit Universitas Diponegoro.

Indrawati. (2015). Metode Penelitian Manajemen dan Bisnis Konvergensi Teknologi Komunikasi dan Informasi. Bandung: PT RefikaAditama.

Inggrid Sinaga, M.AB. (2015). The Effect of Marketing Public Relations on Brand Image. Jurnal Batam State Polytechnics2015

Kambiz Haidarzadeh, Fatemah Torabi. (2013). The Effect of Brand Image and Perceived Public Relations on Customer Loyalty. Jurnal Department of Business Management, Islamic Azad University Iran

Kotler, Philip, Gary Armstrong. (2016). Marketing Management. 14th edition.New Jersey: Pearson Prentice Hall. 
Romadhoni, Muhammad. (2015), Universitas Negri Yogyakarta , Pengaruh Citra Merek (Brand Image) Terhadap Pengambilan Keputusan Pembelian Sepatu Nike pada Mahasiswa FIK UNY. Skripsi.

Romdonah. 2013. Pengaruh inovasi produk, harga dan brand image terhadap keputusan pembelian sepeda motor honda beat (studi kasus pada konsumen dealer honda pratama kurnia kasih Fakultas Ekonomi Universitas Pandanaran Semarang.

Samar Rahi. (2013). Impact Of Customer Value,Public Relations Perceptions And Brand Image On Customer Loyalty In Service Sector Of Pakistan. Jurnal Superior University Lahore Pakistan

Sekaran, Uma dan Bougie, Roger. (2013). Research Methods for Business: A Skill-Building Approach. -6/. New York: Willey.

Sugiyono. (2015). Metode Penelitian Kuantitatif, Kualitatif, dan Kombinasi (Mixed Methods). Bandung: Alfabeta.

Sujarweni, Wiratna. (2015). SPSS Untuk Penelitian.Yogyakarta: Pustaka Baru Press.

Sunarto. 2012. Pengantar Manahemen, Bandung: CVAlfabeta. 